\title{
Determinants of health care decision making autonomy among mothers of children under five years in Ghana: analysis of 2014 Ghana demographic and health survey
}

Henry Ofori Duah' and Isaac Adisah-Atta2*

*Correspondence: iaa408@mail.usask.ca

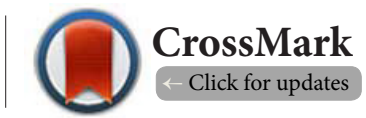

${ }^{1}$ Research Department, Foundation of Orthopaedic and Complex Spine (FOCOS) Hospital, Accra- Ghana.

${ }^{2}$ Department of Political Studies, University of Saskatchewan, 283C Arts Building, Saskatoon, SK S7N 5A5, Canada.

\begin{abstract}
The important role of women's health care decision making autonomy in enhancing the well-being of women and their families cannot be undervalued. As such, this study sought to examine the determinants of health care decision making autonomy among mothers of children less than five years in Ghana using the 2014 Ghana Demographic and Health Survey dataset. A total of 5076 women were included in the analysis. Results showed that $75 \%$ of the Ghanaian women reported exercising health care decision making autonomy either alone (22\%) or jointly with their partners (53\%). Multivariate logistic regression analysis revealed that independent determinants of women's health care decision making autonomy were women's attainment of primary education $(\mathrm{OR}=1.52,95 \% \mathrm{CI} 1.1574$ to 1.9861$)$, secondary education $(\mathrm{OR}=1.46,95 \%$ CI 1.1338 to 1.8784$)$ or higher than secondary education ( $\mathrm{OR}=2.20$, 95\%CI 1.2322 to 3.9547$)$, women's ability to make decisions about their earnings alone (OR=2.42, 95\% CI 1.7570 to 3.3391$)$ or jointly with their partners (OR=9.85, 95\% CI 6.7215 to 14.4364$)$, and having a partner who has attained primary education $(\mathrm{OR}=1.5,95 \% \mathrm{CI} 1.0876$ to 2.0641$)$ or secondary education ( $\mathrm{OR}=1.5,95 \% \mathrm{CI} 1.1740$ to 1.9247$)$. Therefore, encouraging women to pursue education, improving their earnings autonomy whiles promoting education of partners remains a comprehensive way of enhancing women's autonomy in health decision making in order to promote reproductive, maternal and child health.
\end{abstract}

Keywords: Healthcare, decision making, autonomy, women, Ghana

\section{Introduction}

Female healthcare decision-making autonomy is an area that has received attention by researchers due to its growing importance from both human rights and healthcare outcomes perspectives. Generally, autonomy can be defined as having the ability to acquire information and arrive at decisions regarding one's own personal problems [1]. Health decision making autonomy is very critical for the health of women. For example, Alemayehu and Meskele [2] noted that the ability of a woman to visit health care facilities and receive treatment is somewhat dependent on their ability to take personal decisions. However, societal norms, culture, gender roles, gender inequality, religious norms and other socio-cultural factors influence the way women live their lives in developing countries [3].
Existing studies from developing countries have shown that women's autonomy in health care decisions is related to child's health, women's health, utilization of healthcare services and empowerment amongst others [4-9].

Similarly, higher risk of malnutrition has been observed from households where women had little or no autonomy in making household decisions [10]. The ability of women to take health care decision has also been reported in literature to improve the survival rates of their children [11-14].

Regardless of the advantages attributed to women healthcare decision autonomy, power in equalities at the household level between marriage couples has the ability to restrict health decision making autonomy of women which affects other health outcomes. Thus, the position of women in marriages 
in developing countries has made it possible for women to have unequal access to nutrition, education, healthcare as well as the opportunity to earn income for themselves $[9,15,16]$. This limits their utilization of health services which affects reproductive health outcomes and creates problems for their families, communities and their nations at large.

While the above studies represent an enormous contribution to the discourse on women's health decision making autonomy in developing countries, particularly Asia and Africa, there remains a significant dearth in research regarding the determinants of women's health care decision-making autonomy in Ghana,especially among females with children under five years. Most of the previous studies in Ghana tend to focus on the potential impact of women's autonomy on maternal and reproductive health and health services utilization [17-21], with little emphasis on the key determinants of women's health care decision autonomy. Moreover, mothers of children under five years remains an important group to study because health decision making autonomy may have potential impact not only on their health but also on the health of their children less than five years who are in a critical milestone of their development. Knowledge of the determinants will serve as the basis for informed policy actions to improve health care decision making autonomy and avert its potential impacts that have been reported in literature. Therefore, this study was aimed at examining the determinants of health care decision making autonomy among mothers of children under five years in Ghana.

\section{Literature Review}

Determinants of Women's Decision-Making Autonomy Autonomy is multidimensional concept and difficult to quantify. It refers to independence or freedom of the will or one's action and it is explained as the capacity of an agent to act in accordance with objective morality rather than under the influence of desires [4,22]. Women's autonomy is a complex and general term which has contextual meaning and is influenced by personal attributes of women as well as socio-cultural norms of the society [2].

Given the potential health impacts of women health care decision making autonomy, several studies have been conducted particularly in Asia and Africa to investigate its determinant, and factors such as age of women and their partners, educational level of women and partners, income status, having older children, the presence of living children, place of residence (either urban or rural) and cultural factors have been reported [7,23-27].

In Nepal, for example, Allendorf reported that women's education, employment and spousal permission for care seeking were highly associated with women's autonomy [23]. The ability for women to take health care decisions are partly determined by socio-cultural and legal factors [24]. In addition, other studies have reported that being older, having higher education, living in urban centers and being from richer households are the key determinants of women's health care decision making autonomy [25-27].

Similarly, evidence from other studies shows that women's health care decision autonomy was positively associated with women who are older, financially independent, highly educated and had more living children [28-30]. Evidence from Ethiopia shows that as compared to women with no formal education, those with primary and at least secondary education are 2 times and 4 times, respectively, more likely to have health decision making autonomy [31]. However, Kamiya [32] found no statistically significant association between women's autonomy and educational level in Tajikistan but found a positive association between their partners' education and women's autonomy. Thus, highly educated husbands were more likely to involve their wives in household decision making. This observation has been supported by other studies which have also reported a significant positive association between husband's educational status and women's autonomy in seeking health care services for themselves $[25,33]$.

Finally, women's control over earnings may also be an important determinant of health decision making autonomy. According to the basic principles of the gender stratification theory [34-36], economic autonomy of women will increase their access to other kinds of power including sexual and reproductive health.

\section{Materials and Methods}

The study employed analysis of the 2014 Ghana Demographic and Health Survey (DHS) Data. Permission was sought from the DHS program for the data to be accessed and used. The DHS is a prospective nationwide survey that provides vital information related to reproductive health and general health of different countries. The Standard DHS survey is conducted at about 4yearly intervals and the 2014 Ghana DHS was the $6^{\text {th }}$ one to be conducted in Ghana since 1988. Details of the DHS program can be found at http://dhsprogram.com. Since the authors were interested in women with children under five years, the Child Recode dataset was downloaded from the DHS website after obtaining permission. Data was imported into Stata 14 software and preliminary data cleaning was done. The outcome variable which was health care decision making autonomy was identified. During the survey women were asked the question, "Person who usually decides on respondent's health care". There were 5107 cases which responded to the question. Responses included respondent alone, respondent and partner, partner alone, someone else and others.

Analysis was restricted to the main three responses: respondent alone, respondent and partner, partner alone. This is because the responses "someone else" and "others" were not person-specific, and these responses were applicable to only 31 cases. Therefore, 5076 cases were used in the final analysis. The responses of health decision making autonomy were recoded. Originally, respondent alone was coded "1", respondent and partner was coded " 2 ", partner alone was coded " 3 ". Recoding was subsequently done. Women who takes decision 
alone or with their partners were coded 1 (thus 1 and 2 were coded 1) whiles cases where partner alone makes decision were coded 0 (thus 3 was coded 0 ), where " 1 " represents a woman with health care decision making autonomy and " 0 " means no health care decision making autonomy.

Independent variables included women's age, level of education, and earnings autonomy of woman, partner's age and educational level of partners. Bivariate analysis was performed between the original outcome variable (with three levels) and the independent variables. Chi-square test for independence was performed for the outcome variable and categorical independent variables whiles one-way analysis of variance was performed between the outcome and continuous independent variable. The strength of the association was evaluated using logistic regression analysis on the recoded outcome variable (binary variable). Crudes logistic regression estimates were first estimated and all variables were included in a multivariable analysis to estimate the adjusted logistic regression estimates of the determinants of health care decision making autonomy among women.

\section{Results}

Health Care Decision Making Autonomy of women Out of the 5076 women with children under five years included in this analysis, only 1117 representing $22.01 \%$ usually decide on their health care alone, whiles 2703 representing 53.25\% indicated they usually decide jointly with their partners on their health care and 1256 representing $24.78 \%$ had their decisions on health care made by their partners (no autonomy). Women were considered to participate in decision making if they typically make that decision alone or jointly with their partners. As a result, $75.26 \%$ of women had health care decision making autonomy either alone or jointly (See Table 1).

Table 1. Person who usually decides on respondent's health care.

\begin{tabular}{lll}
\hline & Frequency & Percentage \\
\hline Respondent Alone & 1117 & 22.01 \\
Respondent and Husband/Partner & 2703 & 53.25 \\
Husband/Partner Alone & 1256 & 24.74 \\
Total & 5076 & 100 \\
\hline
\end{tabular}

Sources: GDHS 2014 dataset

The degree of health decision making autonomy by background characteristics is shown in the Table 2. Chi-square test for independence showed significant relationship between health decision making autonomy and the following variables: Place of Residence, educational level of women, earnings autonomy of women, and partner's education ( $p<0.05)$. Likewise, one-way analysis of variance (ANOVA) test showed significant difference in the mean age of women for the different levels of health decision making autonomy. Similar findings were found for partners' age. (See Table 2). The magnitude of the association was assessed using logistic regression analysis as shown in Table 3.

Logistic Regression Estimates of the Determinants of Health Care Decision Making Autonomy among women with children under five years in Ghana

Crude analysis revealed that every 1year increase in age of women increases the odds of health care decision making autonomy among women by $1 \%(\mathrm{OR}=1.01,95 \% \mathrm{Cl} 1.0022$ to 1.0217). However, the relationship was not significant in the multivariate analysis ( $\mathrm{OR}=1.01,95 \% \mathrm{Cl} 0.9933$ to 1.0305$)$.

The study further explored the strength of the association between women's education and health decision making autonomy. The odds of having health care decision making autonomy was 2.08 times greater for women who had attained primary education as compared to those who had no education (OR=2.08,95\% $\mathrm{Cl} 1.7356$ to 2.4892$)$. Similarly, as compared to women who had no education, the odds of having health decision making autonomy was 2.28 times greater for women with secondary education ( $\mathrm{OR}=2.28,95 \% \mathrm{Cl} 1.9670$ to 2.6406 ) and 3.93 times greater for women with higher than secondary education $(\mathrm{OR}=3.93,95 \% \mathrm{Cl} 2.5401$ to 6.0825$)$. Moreover, after adjusting for women's age, women's earnings autonomy, residence, partner's age and partner's education, the odds of having health care decision making autonomy was 1.52 times greater for women with primary education $(\mathrm{OR}=1.52$, $95 \% \mathrm{Cl} 1.1574$ to 1.9861$), 1.46$ times greater for women with secondary education $(\mathrm{OR}=1.46,95 \% \mathrm{Cl} 1.1338$ to 1.8784$)$ and 2.20 times greater for women with higher than secondary education ( $\mathrm{OR}=2.20,95 \% \mathrm{Cl} 1.2322$ to 3.9547$)$.

Moreover, the study also explored the strength of association between health care decision making autonomy and autonomy of women over their earnings. As compared to women whose partners are the sole decision makers on their earnings, the odds of having health care decision making autonomy was 2.51 times greater for women who made decisions about their earnings alone $(\mathrm{OR}=2.51,95 \% \mathrm{Cl} 1.8410$ to 3.4309) and 11.58 times greater for women who jointly made decisions about their earnings with their partners (OR=11.58, $95 \% \mathrm{Cl} 7.9671$ to 16.8440 ). Even after adjusting for woman's age, woman's education, residence, partner's age and partner's education, the odds was 2.42 times greater for women who made decisions alone about their earnings ( $O R=2.42,95 \%$ $\mathrm{Cl} 1.7570$ to 3.3391 ) and 9.85 times greater for women who jointly made decisions about their earnings with their partners (OR=9.85,95\% $\mathrm{Cl} 6.7215$ to 14.4364$)$.

In addition, the study explored the strength of the association between place of residence and health care decision making autonomy of women. It was revealed that women who resided in rural areas were $14 \%$ less likely to have health decision making autonomy as compared to their counterparts living in urban areas in Ghana $(\mathrm{OR}=0.86,95 \% \mathrm{Cl} 0.7542$ to 0.9815). However, this relationship was lost after adjusting for woman's age, woman's education, woman's earnings 
Duah et al. Research Journal of Women's Health 2017,

http://www.hoajonline.com/journals/pdf/2054-9865-4-5.pdf

doi: $10.7243 / 2054-9865-4-5$

Table 2. Health decision making autonomy of women with children under five years in Ghana by background characteristics.

\begin{tabular}{|c|c|c|c|c|c|}
\hline & \multicolumn{5}{|c|}{ Person who usually decides on respondent's health care? } \\
\hline & $\begin{array}{l}\text { Respondent } \\
\text { Alone N (\%) }\end{array}$ & $\begin{array}{l}\text { Respondent and } \\
\text { Husband/Partner N (\%) }\end{array}$ & $\begin{array}{l}\text { Husband/Partner } \\
\text { Alone N (\%) }\end{array}$ & $\begin{array}{l}\text { Total } \\
\text { N (\%) }\end{array}$ & P-value \\
\hline \multicolumn{6}{|l|}{ Residence } \\
\hline urban & $509(25.46)$ & $1029(51.48)$ & $461(23.06)$ & 1999(100) & -- \\
\hline Rural & $608(19.76)$ & $1674(54.40)$ & $795(25.84)$ & $3077(100)$ & -- \\
\hline Total & $1117(22.01)$ & $2703(53.25)$ & $1256(24.74)$ & $5076(100)$ & $<0.001$ \\
\hline Woman's Age(yrs) & $32.01^{\mathrm{a}}$ & $31.01^{\mathrm{a}}$ & $30.78^{\mathrm{a}}$ & $31.17^{\mathrm{a}}$ & $<0.001^{*}$ \\
\hline \multicolumn{6}{|l|}{ Educational Level of Women } \\
\hline No education & $376(19.92)$ & $858(45.44)$ & $654(34.64)$ & $1888(1000$ & -- \\
\hline Primary & $213(21.11)$ & $591(58.57)$ & $205(20.32)$ & 1009(100) & -- \\
\hline Secondary & $481(24.33)$ & $1,123(56.80)$ & $373(18.87)$ & 1977(100) & -- \\
\hline Higher Education & $47(23.27)$ & $131(64.85)$ & $24(11.88)$ & $202(100)$ & -- \\
\hline Total & $1117(22.01)$ & $2703(53.25)$ & $1256(24.74)$ & $5076(100)$ & $<0.001$ \\
\hline \multicolumn{6}{|l|}{ Woman's Earnings Autonomy } \\
\hline Respondent Alone & $605(30.74)$ & $834(42.38)$ & $529(26.88)$ & 1968(100) & -- \\
\hline Respondent and Husband/Partner & $139(13.16)$ & $839(79.45)$ & $78(7.39)$ & $1056(100)$ & -- \\
\hline Husband/Partner Alone & $28(15.12)$ & $64(36.16)$ & $85(48.02)$ & $177(100)$ & $<0.001$ \\
\hline \multicolumn{6}{|l|}{ Partners Education } \\
\hline No education & $272(17.46)$ & $736(47.24)$ & $550(35.30)$ & $1,558(100)$ & -- \\
\hline Primary & $132(20.79)$ & $378(59.53)$ & 125(19.69) & $635(100)$ & -- \\
\hline Secondary & $597(25.17)$ & $1275(53.75)$ & $500(21.08)$ & $2372(100)$ & -- \\
\hline Higher Education & $99(21.48)$ & $289(62.69)$ & $73(15.84)$ & $461(100)$ & -- \\
\hline Total & $1100(21.89)$ & $2678(53.28)$ & $1248(24.83)$ & $5026(100)$ & $<0.001$ \\
\hline Partners 'Age (yrs) & $39.23^{\mathrm{a}}$ & $37.78^{\mathrm{a}}$ & $38.91^{\mathrm{a}}$ & $38.38^{\mathrm{a}}$ & $<0.001^{\star}$ \\
\hline
\end{tabular}

Sources: GDHS 2014 dataset: Mean age of under each category; ${ }^{\star} \mathrm{P}$-value for one-way analysis of variance

Table 3. Logistic Regression estimates of the determinants of health Care Decision making Autonomy among women with children under five years in Ghana.

\begin{tabular}{|c|c|c|c|c|c|c|c|c|}
\hline \multirow[b]{3}{*}{ Woman's Age } & \multirow{2}{*}{\multicolumn{3}{|c|}{$\begin{array}{l}\text { OR } \quad 95 \% \text { CI } \\
\text { Crude Estimates }\end{array}$}} & \multirow{2}{*}{ P-value } & \multirow{2}{*}{\multicolumn{3}{|c|}{$\begin{array}{l}\text { OR } \quad 95 \% \text { CI } \\
\text { Adjusted Estimates }\end{array}$}} & \multirow[t]{2}{*}{ P-value } \\
\hline & & & & & & & & \\
\hline & 1.01 & 1.0022 & 1.0217 & 0.016 & 1.01 & 0.9933 & 1.0305 & 0.211 \\
\hline \multicolumn{9}{|l|}{ Woman's Education } \\
\hline No education & Ref & - & & - & - & - & & - \\
\hline Primary & 2.08 & 1.7356 & 2.4892 & $<0.001$ & 1.52 & 1.1574 & 1.9861 & 0.003 \\
\hline Secondary & 2.28 & 1.9670 & 2.6406 & $<0.001$ & 1.46 & 1.1338 & 1.8784 & 0.003 \\
\hline Higher Education & 3.93 & 2.5401 & 6.0825 & $<0.001$ & 2.20 & 1.2322 & 3.9547 & 0.008 \\
\hline \multicolumn{9}{|l|}{ Woman's Earnings Autonomy } \\
\hline Respondent Alone & 2.51 & 1.8410 & 3.4309 & $<0.001$ & 2.42 & 1.7570 & 3.3391 & $<0.001$ \\
\hline Respondent and Husband/Partner & 11.58 & 7.9671 & 16.8440 & $<0.001$ & 9.85 & 6.7215 & 14.4364 & $<0.001$ \\
\hline Husband/Partner Alone & Ref & - & & - & - & - & & - \\
\hline \multicolumn{9}{|l|}{ Residence } \\
\hline Rural & 0.86 & 0.7542 & 0.9815 & 0.025 & 0.87 & 0.7109 & 1.0563 & 0.156 \\
\hline Partners Age & 0.99 & 0.9858 & 0.9988 & 0.022 & 0.99 & 0.9782 & 1.0040 & 0.178 \\
\hline \multicolumn{9}{|l|}{ Partner's Education } \\
\hline No education & Ref & - & & - & - & - & & - \\
\hline Primary & 2.23 & 1.7838 & 2.7781 & $<0.001$ & 1.50 & 1.0876 & 2.0641 & 0.013 \\
\hline Secondary & 2.04 & 1.7701 & 2.3575 & $<0.001$ & 1.50 & 1.1740 & 1.9247 & 0.001 \\
\hline Higher Education & 2.90 & 2.2121 & 3.8019 & $<0.001$ & 1.42 & 0.9352 & 2.1463 & 0.100 \\
\hline
\end{tabular}


autonomy, partner's age and partner's education in the multivariate analysis.

The study also explored the strength of the association between level of education of partners and health care decision making autonomy. As compared to women whose partners had no education, the odds of having health decision making autonomy was 2.23 times greater for women whose partners had primary education $(\mathrm{OR}=2.23,95 \% \mathrm{Cl} 1.7838$ to 2.7781$)$, 2.04 times greater for those whose partners had secondary education $(\mathrm{OR}=2.04,95 \% \mathrm{Cl} 1.7701$ to 2.3575$)$ and 2.90 times greater for women whose partners had attained higher than secondary education ( $\mathrm{OR}=2.90,95 \% \mathrm{Cl} 2.2121$ to 3.8019$)$. In the multivariate analysis, odds of health care decision making autonomy was 1.5 times greater for women whose partners had attained primary education $(\mathrm{OR}=1.5,95 \% \mathrm{Cl} 1.0876$ to 2.0641) and 1.5times greater for those whose partners had attained secondary education ( $\mathrm{OR}=1.5,95 \% \mathrm{Cl} 1.1740$ to 1.9247$)$ However, the association between higher than secondary education of partners and health care decision making autonomy of women was lost in the multivariate analysis (Table 3). There was no significant association between partner's age and health care decision making autonomy after logistic regression analysis.

\section{Discussion}

The concept of health decision making autonomy of women has been an area of interest to public health practitioners and social scientists because of its impact on reproductive health choices, maternal and child health [10-14]. This study aimed at assessing the determinants of health care decision making autonomy among mothers of children less than five years in Ghana.

We found that $75.26 \%$ of women had health care decision making autonomy either alone or jointly with their partners. This finding is higher than that reported by Alemayehu and Meskele [2] in Ethiopia in which $58.4 \%$ of their study participants had autonomy in making health care decisions either alone or jointly with their partners. The incongruent findings observed may be explained by the context and setting of the respective studies. While the study in Ethiopia sampled only participants from rural communities, this current study included participants from both rural and urban communities in Ghana hence this may explain the disparities.

This study also identified some determinants of health care decision making autonomy of women in Ghana. Multivariate logistic regression showed that women's education, women's earnings autonomy and partner's education were independent predictors of women's healthcare decision making autonomy.

After adjusting for women's age, women's earnings autonomy, residence, partner's age and partner's education, we found that primary, secondary and higher than secondary education of women in Ghana were all associated with higher odds of health care decision making autonomy as compared to women with no formal education. The odds were 1.52 times greater for those who had attained primary education, 1.46 times greater for women with secondary education, and 2.20 times greater for women with higher than secondary education (Table 3). This finding is supported by Nigatu et al [31], who reported that women in Ethiopia who have primary, secondary, and postsecondary education are about two and four times more likely to have higher autonomy compared to women with no formal education. The impacts of higher education on autonomy have also been reported by other studies [28-30]. The reason may be that educated women are more aware of their right to free choice and might be more capable of exercising their will as far as health care decision is concerned, either alone or with their partners. Moreover, increasing education may be associated with better chances of being gainfully employment which may confer greater autonomy to them as compared to those with no formal education. Furthermore, it is possible that power disparities within marriage, which may negatively influence women's healthcare decision-making autonomy, may also be lessened with increasing education of women. Unsurprisingly, we found that attaining higher than secondary education was associated with the greatest odds of health care decision making autonomy.

This study also revealed significant positive relationship women's control over their own earnings and health care decision making autonomy. Even after adjusting for woman's age, woman's education, residence, partner's age and partner's education, the decision making autonomy was 2.42 times greater for women who made decisions alone about their earnings and 9.85 times greater for women who jointly made decisions about their earnings with their partners. Thus, this observation evidently shows that having control over earnings is a significant independent determinant of health care decision making autonomy among women. This finding is consistent with the basic principles of the gender stratification theory which argues that women's economic power determines their access to other kinds of power [34-36]. Therefore, having autonomy over their earnings facilitated the attainment of health care decision making autonomy of women in Ghana.

In addition, this study found a significant positive relationship between educational levels of partners and women's healthcare decision making autonomy. Multivariate logistic regression analysis revealed that the odds of health care decision making autonomy was 1.5 times greater for women whose partners had attained primary education and 1.5times greater for those whose partners had attained secondary education. Table 3. This implies that educated partners tends to promote health decision making autonomy of women. This finding is consistent with the studies by Kamiya [32] and Facha et al. [33] who reported positive association between husbands' education and women's health autonomy. Nevertheless, it is important to note that this association was limited to primary and secondary education of partners but not partners who 
had higher than secondary education.

In the crude logistic regression analysis, it was found that age of women, age of partner, and place of residence were significant predictors of health care decision making autonomy of women but this effect was lost in multivariate analysis. Though some studies have reported greater autonomy with increasing maternal age [2,37-39], the present study shows that age of woman, age of partner, and place of residence are not an independent determinants of health care decision making autonomy in the presence of other influential factors such as women's education, women's earnings autonomy, and partner's education.

\section{Conclusion}

The essential role of women's health care decision making autonomy in enhancing the well-being of themselves, their children and the entire family cannot be underestimated. As such, this study sought to examine the determinants of health care decision making autonomy among Ghanaian women with children less than five years. About $75 \%$ of the Ghanaian women reported exercising health care decision making autonomy either alone (22\%) or jointly with their partners (53\%). This study revealed that a women's health care decision making autonomy is independently influenced by their educational level, control over earnings and partner's education. Therefore, motivating women to pursue education, improving their earnings autonomy through employment and capacity building whiles promoting the education of their partners remains a comprehensive strategy of enhancing women's autonomy in health care decision making in order to promote reproductive, maternal and child health. This all-inclusive strategy is needed to be implemented in order to potentially reduce power disparities in marriages and empower women to have full control of their healthcare decisions. This study finally recommends that women should be mobilized, encouraged to pursue higher education, enabled to access economic resources and provided with support to challenge the traditional norms that underlie gender inequalities in Ghana.

\section{Competing interests}

The authors declare that they have no competing interests.

\section{Authors' contributions}

\begin{tabular}{|l|c|c|}
\hline Authors' contributions & HOD & IAA \\
\hline Research concept and design & $\checkmark$ & $\checkmark$ \\
\hline Collection and/or assembly of data & $\checkmark$ & $\checkmark$ \\
\hline Data analysis and interpretation & $\checkmark$ & $\checkmark$ \\
\hline Writing the article & $\checkmark$ & $\checkmark$ \\
\hline Critical revision of the article & $\checkmark$ & $\checkmark$ \\
\hline Final approval of article & $\checkmark$ & $\checkmark$ \\
\hline Statistical analysis & $\checkmark$ & -- \\
\hline
\end{tabular}

\section{Acknowledgments}

We are grateful to the DHS staff and teams that carried out and conducted these survey in Ghana and have made the data publicly available.

\section{Publication history}

EIC: Erich Cosmi, University of Padua, Italy.

Received: 30-Sep-2017 Final Revised: 11-Nov-2017

Accepted: 17-Nov-2017 Published: 10-Dec-2017

\section{References}

1. Dyson T and Moore M. On kinship structure, female autonomy, and demographic behavior in India. Population and Development Review. 1983; 9:35-60. | Article

2. Alemayehu $\mathrm{M}$ and Meskele $\mathrm{M}$. Health care decision making autonomy of women from rural districts of Southern Ethiopia: a community based cross-sectional study. Int J Womens Health. 2017; 9:213-221. | Article | PubMed Abstract | PubMed FullText

3. Woldemicael G and Tenkorang EY. Women's autonomy and maternal health-seeking behavior in Ethiopia. Matern Child Health J. 2010; 14:988-98. | Article | PubMed

4. Dangal G and Bhandari T. R. Women's autonomy: new paradigm in maternal health care utilization. Cell. 2014; 977:9851055036. | Pdf

5. Fotso JC, Ezeh AC and Essendi $\mathrm{H}$. Maternal health in resource-poor urban settings: how does women's autonomy influence the utilization of obstetric care services? Reprod Health. 2009; 6:9. | Article | PubMed Abstract | PubMed FullText

6. Bloom SS, Wypij D and Das Gupta M. Dimensions of women's autonomy and the influence on maternal health care utilization in a north Indian city. Demography. 2001; 38:67-78. I PubMed

7. Matthews, Zoë, Radhika Ramasubban, Bhanwar Rishyasringa and Will Stones. Autonomy and maternal health-seeking among slum populations of Mumbai. 2003.

8. Sahu D, Dutta T, Kumar S, Mishra N. R, Neogi S, Mondal S and LevittDayal M. Effects of Women's Autonomy and Male Involvement on Reproductive and Child Health (RCH) Service Utilization in Uttar Pradesh. Open Journal of Preventive Medicine. 2016; 6:260.

9. Ahmed S, Creanga AA, Gillespie DG and Tsui AO. Economic status, education and empowerment: implications for maternal health service utilization in developing countries. PLoS One. 2010; 5:e11190. | Article | PubMed Abstract | PubMed FullText

10. Mullany BC, Hindin MJ and Becker S. Can women's autonomy impede male involvement in pregnancy health in Katmandu, Nepal? Soc Sci Med. 2005; 61:1993-2006. I Article I PubMed

11. Kishor S. Empowerment of women in Egypt and links to the survival and health of their infants. In: Presser H, Sen G, editors. Women's empowerment and demographic processes: Moving beyond Cairo. New York: Oxford University Press. 2000; 118-158.

12. Fantahun M, Berhane $Y$, Wall S, Byass $P$ and Hogberg U. Women's involvement in household decision-making and strengthening social capital-crucial factors for child survival in Ethiopia. Acta Paediatr. 2007; 96:582-9. | Article | PubMed Abstract | PubMed FullText

13. Anderson S and Eswaran M. What determines female autonomy? Evidence from Bangladesh. Journal of Development Economics. 2009; 90:179-91.

14. Brunson EK, Shell-Duncan B and Steele M. Women's autonomy and its relationship to children's nutrition among the Rendille of northern Kenya. Am J Hum Biol. 2009; 21:55-64. | Article | PubMed Abstract | PubMed FullText

15. Asian development banks to promote greater empowerment for Nepal's most disadvantaged women. 2017.

16. Tekelab T, Yadecha B and Melka AS. Antenatal care and women's decision making power as determinants of institutional delivery in rural area of Western Ethiopia. BMC Res Notes. 2015; 8:769. | Article | PubMed Abstract | PubMed FullText 
17. Issah K, Nang-Beifubah A and Opoku CF. Maternal and neonatal survival and mortality in the Upper West Region of Ghana. Int J Gynaecol Obstet. 2011; 113:208-10. | Article | PubMed

18. Ross K. L, Zereyesus Y. A, Shanoyan A and Amanor-Boadu V. The health effects of women empowerment: recent evidence from Northern Ghana. International Food and Agribusiness Management Review. 2015; 18:127. | Pdf

19. Severin D.D. Gender Relations and Maternal Health Services: On Prenatal Care Utilization in Rural Northern Ghana, International Institute of Social Science, The Hague, The Netherlands. 2011.

20. Allendorf K. Couples' reports of women's autonomy and health-care use in Nepal. Stud Fam Plann. 2007; 38:35-46. | Article | PubMed

21. Cofie LE, Barrington C, Singh K, Sodzi-Tettey S and Akaligaung A. Birth location preferences of mothers and fathers in rural Ghana: Implications for pregnancy, labor and birth outcomes. BMC Pregnancy Childbirth. 2015; 15:165. | Article | PubMed Abstract | PubMed FullText

22. Furuta M and Salway S. Women's position within the household as a determinant of maternal health care use in Nepal. Int Fam Plan Perspect. 2006; 32:17-27. | Article | PubMed

23. Allendorf K. Couples' reports of women's autonomy and health-care use in Nepal. Stud Fam Plann. 2007; 38:35-46. | Article | PubMed

24. Senarath $U$ and Gunawardena NS. Women's autonomy in decision making for health care in South Asia. Asia Pac J Public Health. 2009; 21:137-43. | Article | PubMed

25. Haque SE, Rahman M, Mostofa MG and Zahan MS. Reproductive health care utilization among young mothers in Bangladesh: does autonomy matter? Womens Health Issues. 2012; 22:e171-80. | Article | PubMed

26. Sathar ZA and Kazi S. Women's autonomy in the context of rural Pakistan. The Pakistan Development Review. 2000; 39:89-110.

27. Mason $\mathrm{KO}$ and Smith $\mathrm{HL}$. Husbands' versus wives' fertility goals and use of contraception: the influence of gender context in five Asian countries. Demography. 2000; 37:299-311. | PubMed

28. Acharya DR, Bell JS, Simkhada P, van Teijlingen ER and Regmi PR. Women's autonomy in household decision-making: a demographic study in Nepal. Reprod Health. 2010; 7:15. | Article | PubMed Abstract | PubMed FullText

29. Becker S, Fonseca-Becker F and Schenck-Yglesias C. Husbands' and wives' reports of women's decision-making power in Western Guatemala and their effects on preventive health behaviors. Soc Sci Med. 2006; 62:2313-26. | Article | PubMed

30. Das B and Tarai D. Decision-making and fertility behaviour: A comparative analysis of Scheduled Caste and Scheduled Tribe women in Odisha. Social Change. 2011; 41:233-249. | Article

31. Nigatu D, Gebremariam A, Abera M, Setegn T and Deribe K. Factors associated with women's autonomy regarding maternal and child health care utilization in Bale Zone: a community based cross-sectional study. BMC Womens Health. 2014; 14:79. | Article | PubMed Abstract | PubMed FullText

32. Kamiya Y. Women's autonomy and reproductive health care utilisation: empirical evidence from Tajikistan. Health Policy. 2011; 102:304-13. | Article I PubMed

33. Facha W, Alemayehu M, Meskele M and Fikadu T. Couples' Opinion and Women's Utilization of Postnatal Care Service in Wolaita Zone, Southern Ethiopia: A Community Based Mixed Study. Science. 2017; 5:276-281. | Article

34. Blumberg R. L. A general theory of gender stratification. Sociological theory. 1984; 23-101.

35. Blumberg RL. Income under female versus male control: hypotheses from a theory of gender stratification and data from the Third World. $J$ Fam Issues. 1988; 9:51-84. | PubMed

36. Wermuth L. A and Monges M. M. A. K. R. Gender stratification: a structural model for examining case examples of women in lessdeveloped countries. Frontiers: A Journal of Women Studies. 2002; 23:1-22. | Article

37. Delbiso TD. Gender power relations in reproductive decision-making: The case of migrant weavers of Addis Ababa, Ethiopia. Journal of
Science \& Development; 2014; 2:59-71. | Pdf

38. Chapagain M. Conjugal power relations and couples' participation in reproductive health decision-making: Exploring the link in Nepal. Gender, Technology and Development. 2006; 10:159-189. | Article

39. Mekonnen A and Asrese K. Household decision making status of women in dabat district, north west Ethiopia, 2009 Gc. Science Journal of Public Health; 2014; 2:111-118

\section{Citation:}

Duah HO and Adisah-Atta I. Determinants of health care decision making autonomy among mothers of children under five years in Ghana: analysis of 2014 Ghana demographic and health survey. Res J Womens Health. 2017; 4:5. http://dx.doi.org/10.7243/2054-9865-4-5 